\title{
Fully lignocellulose-based PET analogues for the circular economy
}

\author{
Xianyuan Wu ${ }^{a}$, Maxim V. Galkin ${ }^{a}$, Zhuohua Sun $^{* b}$ and Katalin Barta*a,c \\ ${ }^{a}$ Stratingh Institute for Chemistry, University of Groningen, Groningen, The Netherlands. \\ ${ }^{\mathrm{b} B e i j i n g ~ A d v a n c e d ~ I n n o v a t i o n ~ C e n t e r ~ f o r ~ T r e e ~ B r e e d i n g ~ b y ~ M o l e c u l a r ~ D e s i g n, ~ B e i j i n g ~ F o r e s t r y ~ U n i v e r s i t y, ~ N o . ~} 35$ \\ Tsinghua East Road Haidian District, Beijing, 100083, P. R. China. \\ 'Department of Chemistry, Organic and Bioorganic Chemistry, University of Graz, Heinrichstrasse 28/II, $8010 \mathrm{Graz}$, \\ Austria \\ *Correspondence to: katalin.barta@uni-graz.at
}

\begin{abstract}
Polyethylene terephthalate (PET) is one of the most abundantly used polymers, but also a significant pollutant in oceans. Due to growing environmental concerns, novel PET alternatives are highly sought after. Here we present readily recyclable PET analogues made entirely from woody biomass. Central to the concept is a two-step noble metal free catalytic sequence (Cu20-PMO catalyzed reductive catalytic fractionation and Raney $\mathrm{Ni}$ mediated catalytic funneling) that allows for obtaining a single aliphatic diol (PC) in $56.4 \%$ efficiency as well as other product streams convertible to fuels. The diol PC is co-polymerized with methyl esters of terephthalic acid (TPA) and furan dicarboxylic acid (FDCA), both of which can be derived from the cellulose residues, to obtain polyesters with competitive $\mathrm{Mw}$ and thermal properties $\left(T_{g}\right.$ of $70-90^{\circ} \mathrm{C}$ ). The new polymers show excellent chemical recyclability in methanol and are thus promising candidates for the circular economy.
\end{abstract}

\section{Introduction}

With an annual production of 70 million tons globally, polyethylene terephthalate (PET) is one of the most widely used polymers worldwide, indispensable for the manufacturing of packaging material, clothing, fibers and single-use beverage bottles ${ }^{1,2}$. However, its accumulation in landfills and oceans has been estimated to reach up to 530 million tons to date ${ }^{2}$, which accounts for near-catastrophic environmental pollution ${ }^{2-4}$. Moreover, most of the PET is still, typically, produced from fossil resources by copolymerization of ethylene glycol (EG) and terephthalic acid (TPA $)^{[5]}$.

Thus, there is tremendous incentive to obtain readily recyclable ${ }^{6,7}$ or upcyclable ${ }^{8}$, fully bio-based PET alternatives ${ }^{9,10}$ in order to implement circular economy approaches ${ }^{11-15}$. This will require the development of new, robust catalytic methods and comprehensive biorefinery strategies ${ }^{16-19}$.

A well-known emerging industrial approach is the replacement of petrol-based TPA with furan dicarboxylic acid (FDCA) from sugar derived $5-\mathrm{HMF}^{20,21}$. Other laboratory scale examples focus on pathways to source $\mathbf{E G}^{22,23}$ and TPA from biomass ${ }^{24-27}$. Lignin-derived monomers, such as ferulic or syringic acids, have been investigated for the preparation of PET, PET mimics and PET reinforced plastics, ${ }^{8,9,29}$ (Fig. 1a). Beckham and coworkers developed a smart upcycling route where PET was modified by EG and muconic acid to give an unsaturated polyester, which was subjected to cross-linking to produce fiberglass reinforced plastics ${ }^{8}$.

Reductive catalytic fractionation $(\mathbf{R C F})^{30-33}$ has shown a powerful strategy for obtaining high yields of aromatic monomers from lignocellulose that can be converted to a variety of polymer building blocks including TPA $^{[24]}$ but also others such as 4-propylcyclohexanol ${ }^{34,35}$, bisphenol 5,5-methylenebis(4- $n$-propylguaiacol) ${ }^{36}$ and $3,3^{\prime}$-ethylenebis(4-n-propylsyringol) ${ }^{37}$ for making diverse types of polymers. Epp's group synthesized highperformance adhesives from 4- $n$-propylsyringol and RCF mixtures ${ }^{38}$.

Here we present a comprehensive biorefinery strategy for constructing novel PET analogues, as well as gasoline range and jet-range fuels, based entirely on woody biomass (Fig. 1b). In our unique approach, lignin 
gives the aliphatic diol building block, while cellulose may provide the necessary aromatic diacid components (FDCA and TPA) in the developed polyesters. Central to the method is the catalytic funneling ${ }^{24,39-42}$ of native lignin by a non-noble metal two step catalytic sequence, which results in 4-(3-hydroxypropyl) cyclohexan-1-ol (PC), isolated as single compound in $56.4 \%$ efficiency as well as other product streams convertible to gasoline range cyclohexane derivatives and high energy density fuel range bicyclic alkanes. Notably, this funneling strategy allows overcoming tedious and expensive product isolation and purification protocols, providing a single polymer building block PC from complex biomass feed as well as other usable product streams. This leads to overall excellent lignocellulose utilization and the synthesis of fully wood-based polyesters. The new polyesters (poly (PC, TPA) and poly (PC, FDCA) display excellent thermal properties $\left(T_{g}=\right.$ between $\left.75-90^{\circ} \mathrm{C}\right)$ that compare favorably to commercially available PET and are readily recyclable in methanol. Overall, these fully bio-based polyesters represent promising candidates for the circular economy.

a) Previous work

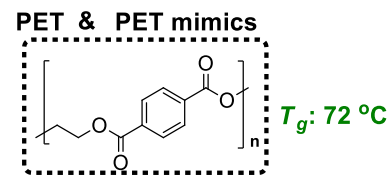

PET

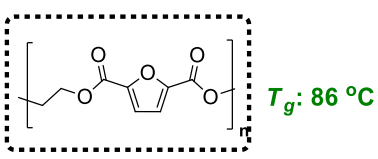

PEF

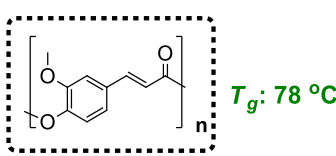

PHFA

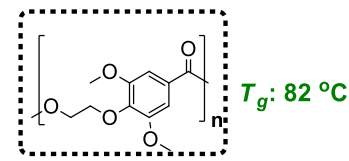

PEVA

PET reinforced plastics

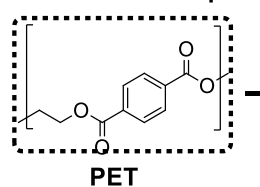

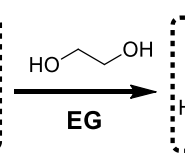

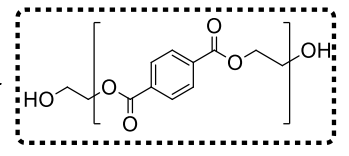

Deconstructed PET

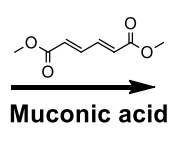

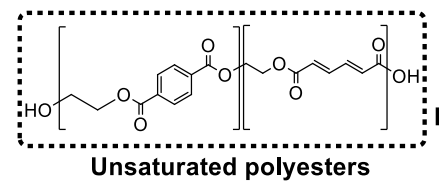

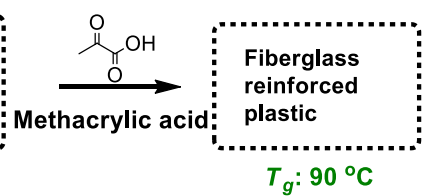

b) Present work
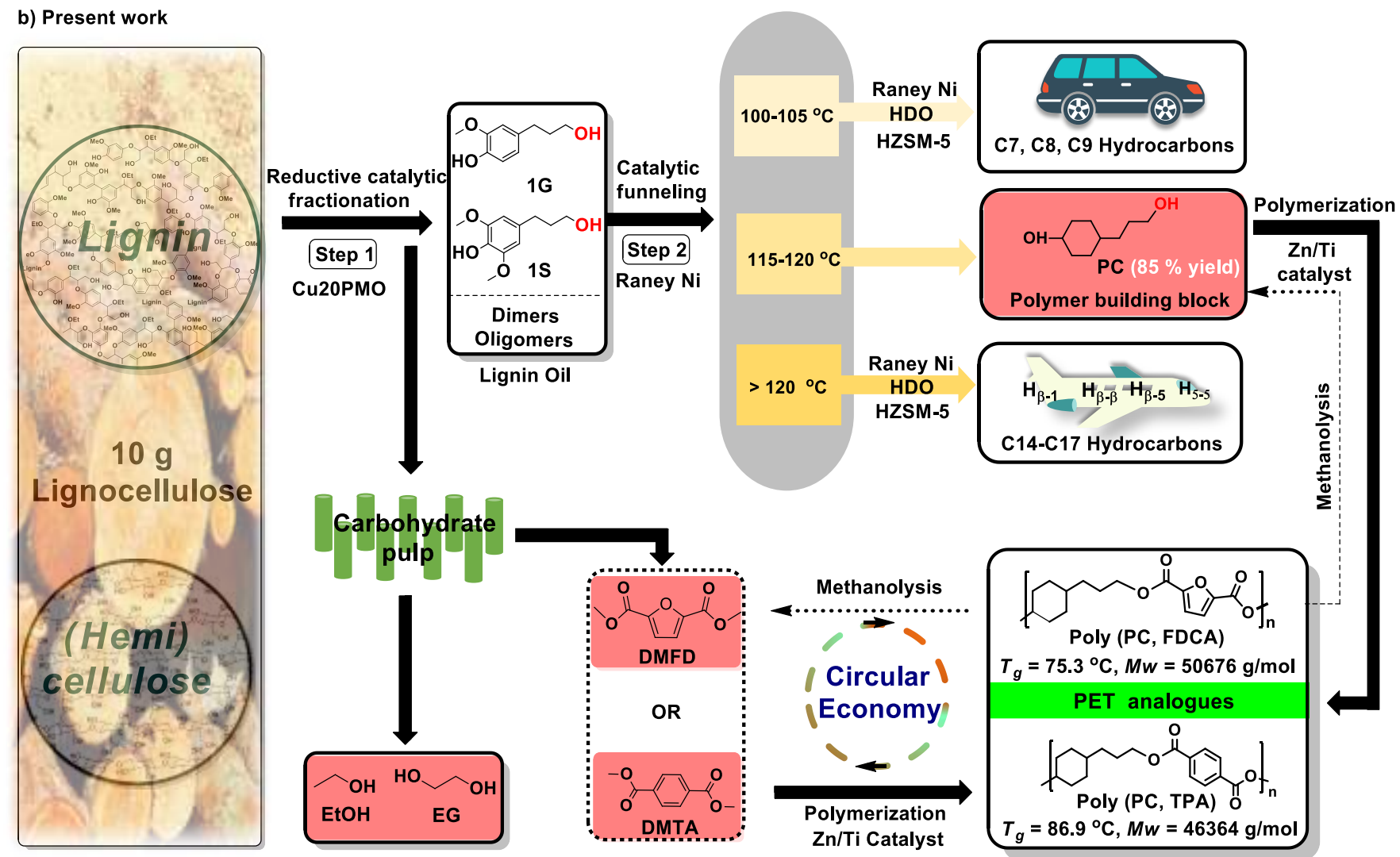

Fig. 1 a) Previous representative work to produce bio-based PET, PET mimics and PET reinforced plastics. b) A comprehensive biorefinery strategy to produce fully lignocellulose-based, recyclable PET analogues and other valuable 
products following three key steps: (1) Reductive catalytic fractionation (RCF) of lignocellulose over $\mathrm{Cu}_{20}-\mathrm{PMO}$ catalyst to give a crude lignin oil rich in $\mathbf{1 G}$ and $\mathbf{1 S}$ bearing a primary alcohol functionality; (2) Catalytic funneling of the ethyl-acetate extracted RCF mixtures to PC diol and other product streams using Raney nickel/isopropanol, (3) Co-polymerization of PC with methyl esters of FDCA and TPA to give fully bio-based and recyclable polyesters poly (PC, TPA) and poly (PC, FDCA). Potential valorization of the carbohydrate residues obtained upon RCF of the same lignocellulose source to the aromatic diacids FDCA and TPA necessary for the co-polymerization, while any surplus of cellulose can be converted to bioethanol and/or ethylene glycol (EG) (see Supplementary Section 1.6 for more details)

\section{Results and discussion}

\section{Catalytic defunctionalization of lignin-derived platform chemicals}

We have previously reported on the RCF of various lignocellulose species with excellent selectivity to 4-npropanolguaiacol (1G) using pine, and to a mixture of 4-n-propanolguaiacol (1G) and 4-n-propanolsyringol (1S) using poplar/beech lignocellulose, with $\mathrm{Cu}_{20} \mathrm{PMO}$ as a catalyst ${ }^{43}$. The advantage of this method is that $\mathbf{1 G}$ and $\mathbf{1 S}$ feature an aliphatic alcohol moiety. Thus, first we envisioned the catalytic funneling of these aromatic platform chemicals to the aliphatic diol PC to test its suitability for making novel PET analogues. This should be achieved by highly selective demethoxylation/hydrogenation, while maintaining this primary alcohol functionality; a challenging reaction, since the $\gamma$-alcohol may participate in direct hydrogenolysis or undergo a dehydrogenation/decarbonylation cascade especially at higher temperatures ${ }^{43}$. In fact, such reactions have been typically investigated using simpler substrates or lignin derived bio-oils, resulting in higher degree of defunctionalization ${ }^{44,45}$.

To circumvent the above-mentioned pathways, we first evaluated a range of commercially available heterogeneous catalysts (Fig. 2A, Table S1) that may exhibit good reactivity in demethoxylation/hydrogenation under relatively mild conditions $\left(100^{\circ} \mathrm{C}\right.$, for $2 \mathrm{~h}$, using 10 bar $\mathrm{H}_{2}$ ) in isopropanol as a solvent, using $1 \mathrm{G}$ as a substrate. Both $\mathrm{Ni} / \mathrm{\gamma}-\mathrm{Al}_{2} \mathrm{O}_{3}$ and $\mathrm{Ni} / \mathrm{C}$ were inactive, and only moderate success was achieved with $\mathrm{Ni} / \mathrm{SiO}_{2}-\mathrm{Al}_{2} \mathrm{O}_{3}$. Noble metal catalysts demonstrated high 1 G conversions ( $83.4 \%, \mathrm{Pd} / \mathrm{C}$ and $100 \%, \mathrm{Ru} / \mathrm{C}$ ), but low selectivity for the desired diol PC (11.5\%, Pd/C and $29.9 \%, \mathrm{Ru} / \mathrm{C}$ ), while displaying higher selectivity to 4-(3-hydroxypropyl)-2methoxycyclohexanol (1) $(51.6 \%, \mathrm{Ru} / \mathrm{C}, 30.5 \%, \mathrm{Pd} / \mathrm{C})$ and other side products such as 4-ethylcyclohexanol (2), 4propylcyclohexanol (3), 4-propylphenol (2H) and 4-(3-hydroxypropyl)phenol (1H).

Gratifyingly, using Raney nickel lead to 84.8 \% 1 G conversion and $84.4 \%$ PC selectivity. Diol PC was obtained as a 1:2 mixture of cis : trans isomers (determined by GC-FID (Fig. S27 b) and ${ }^{1} \mathrm{H}-\mathrm{NMR}$ (Fig. S31)). Further evaluating a range of solvents using Raney nickel $\left(10 \mathrm{bar} \mathrm{H}_{2}\right.$, at $\left.100^{\circ} \mathrm{C}\right)$, it was confirmed that isopropanol is a superior reaction medium (Fig. 2C, Table S2), in line with excellent previous work ${ }^{44}$ using this solvent/catalyst combination for transfer hydrogenation purposes. Optimization led to $84.8 \%$ yield of PC at $120^{\circ} \mathrm{C}$ for $2 \mathrm{~h}$, applying 10 bar $\mathrm{H}_{2}$ (Fig. 2D, Table S4). The addition of $\mathrm{H}_{2}$ gas appeared necessary to suppress the dehydrogenation/decarbonylation cascade otherwise leading to loss of selectivity (Fig. 2B, Table S3). The reaction mixture obtained under optimized conditions consisted of compounds PC, 1, and $\mathbf{2}$.

Based on the product distribution, PC could have formed through demethoxylation, followed by hydrogenation or vice versa. To gain more insight into plausible reaction pathways from $1 \mathbf{G}$ leading to PC, further kinetic studies were undertaken (Supplementary Section 2.3-2.4). Reaction intermediates $\mathbf{1 H}$ and $\mathbf{1}$ showed significant difference in reactivity when subjected to optimized reaction conditions (Table S6-S7, Fig. 2F). While 1 displayed very low conversion, $\mathbf{1 H}$ was readily hydrogenated to the desired product PC. As comparison, the aromatic ring hydrogenation rate of $\mathbf{1 H}\left(k_{2}=0.4400 \mathrm{~min}^{-1}\right)$ was much higher than demethoxylation of $\mathbf{1}\left(k_{4}=10^{-7}\right.$ $\left.\mathrm{min}^{-1}\right)$. Furthermore, the rate of hydrogenation of $1 \mathbf{G}$ to $1\left(k_{3}=0.0017 \mathrm{~min}^{-1}\right)$ and the rate of demethoxylation of $1 \mathbf{G}$ to $\mathbf{1 H}\left(k_{1}=0.0082 \mathrm{~min}^{-1}\right)$ were comparable. Summing up these observations, the following order was observed: $k_{2}>k_{1}>k_{3}>k_{4}$, where demethoxylation of $\mathbf{1 G}$ to $\mathbf{1 H}$ is the rate limiting step (Fig. 2E). Therefore, we assume that 
the catalytic conversion of $\mathbf{1 G}$ proceeds through demethoxylation to give compound $\mathbf{1 H}$, followed by its hydrogenation to $\mathbf{P C}$, while hydrogenation of $\mathbf{1 G}$ to intermediate $\mathbf{1}$ is considered as a parallel side reaction, and other side reactions are relatively slow (Fig. 2 E, Scheme S1).

Next, $1 \mathrm{~S}$ comprising extra functionality was evaluated as substrate, using Raney nickel catalyst under previously optimized reaction conditions $\left(140^{\circ} \mathrm{C}, 20 \mathrm{bar}, 2 \mathrm{~h}\right.$, isopropanol). Gratifyingly, PC was obtained in $84.6 \%$ yield (Table 1). Moreover, in order to establish a catalytic funneling strategy, model mixtures of 1G/1S and $\mathbf{1 G} / \mathbf{1 S} / \mathbf{1 H}$ that are main components of bio-oils derived by RCF of hardwood or switchgrasses, were successfully converted into PC with excellent yield of $84.8 \%$ and $86.3 \%$ respectively. 
A

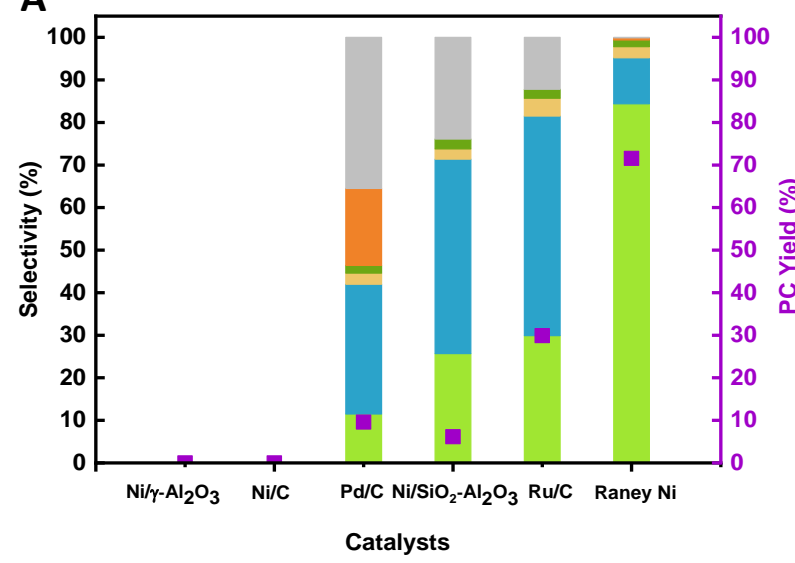

C

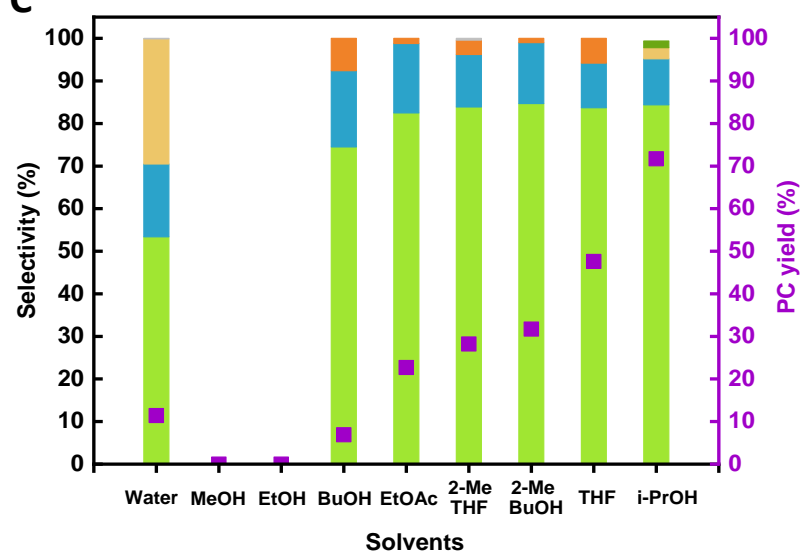

B

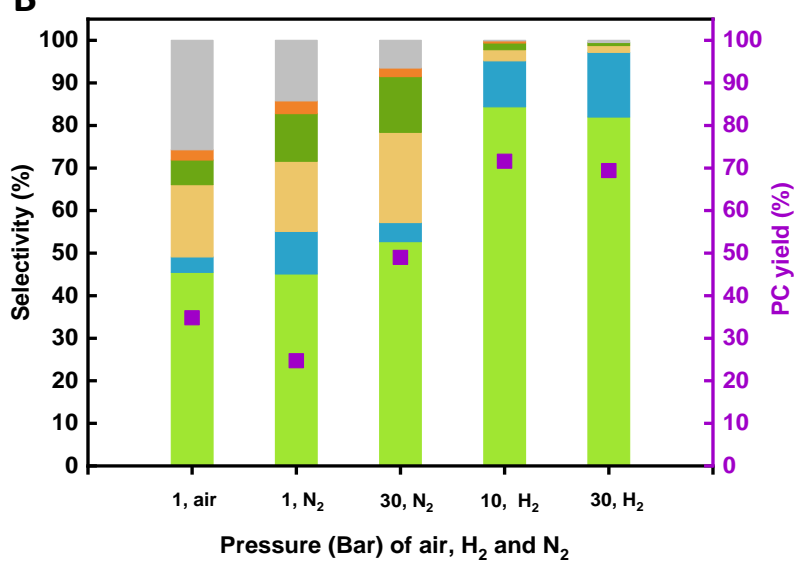

D

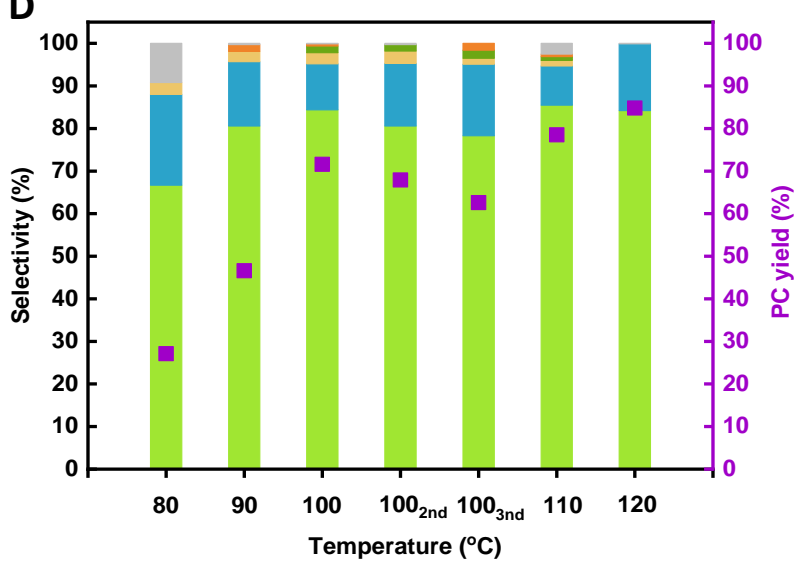

Others
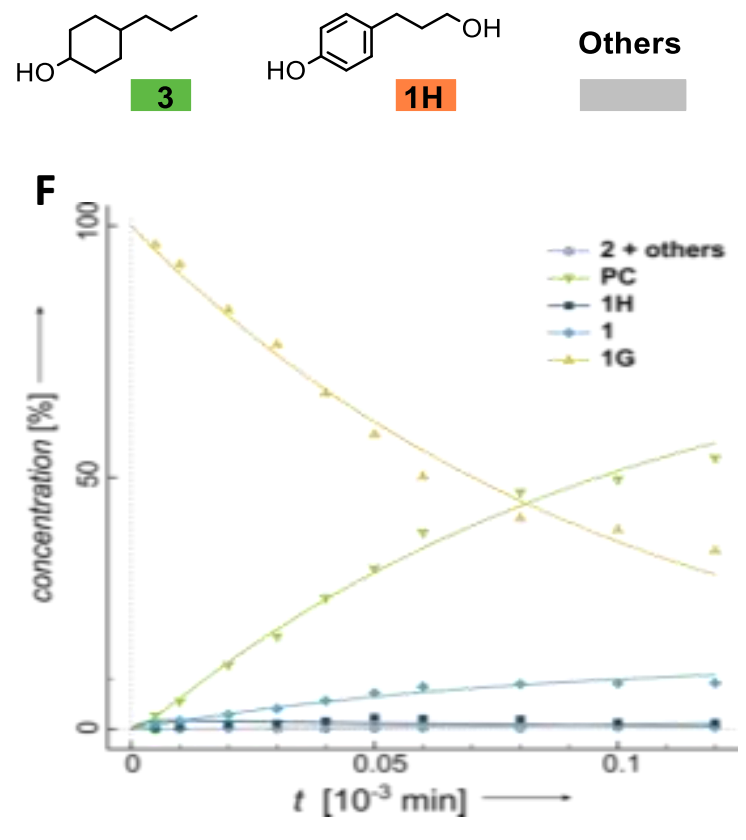

Fig. 2 Establishing optimal reaction conditions for the catalytic conversion of $\mathbf{1 G}$ to PC (A-D); Standard reaction conditions unless otherwise specified: $\mathbf{1 G}$ (1.1 mmol, $0.200 \mathrm{~g}), 1 \mathrm{~g}$ Raney nickel, $2 \mathrm{~h}, 15 \mathrm{~mL}$ solvent, $10 \mathrm{mg}$ dodecane. Screening of A) commercially available heterogeneous metal catalysts; B) different gas phase: air, $\mathrm{N}_{2}$ and $\mathrm{H}_{2}$; C) various solvents; D) reaction temperature; (A-D) For numerical values see Supplementary Table S1-S4; Conversion and yield values determined by GC-FID using calibration curves and internal standard; E) Proposed reaction network and calculated apparent rate constants from data fitting, utilizing the DynaFit software $\left(k_{\mathrm{app}}\right.$ in $\left.10^{-3} \cdot \mathrm{min}^{-1}\right)$; F) Fitting of the experimental data for catalytic conversion of 1G, $1,1 \mathrm{H}$ and PC over wet Raney nickel catalyst. Reaction conditions: $1.1 \mathrm{mmol}$ substrate, $0.500 \mathrm{~g}$ Raney nickel, $100{ }^{\circ} \mathrm{C}, 20 \mathrm{bar} \mathrm{H}_{2}$, $20 \mathrm{~mL}$ isopropanol, $20 \mathrm{mg}$ dodecane as internal standard. Data is presented in details in Supplementary Table S5-S7. 
Table 1. Catalytic conversion of $\mathbf{1 G}, \mathbf{1 H}, \mathbf{1 S}$ or mixtures or lignin oil rich in $\mathbf{1 G}$ or $\mathbf{1 G / 1 S}$ mixture to $\mathrm{PC}$ diol $^{[\mathrm{ad}]}$.

\begin{tabular}{|c|c|c|c|c|c|c|c|c|c|c|c|}
\hline \multirow[b]{2}{*}{ Entry } & \multirow[b]{2}{*}{ Substrates } & \multirow{2}{*}{$\begin{array}{l}T \\
{\left[{ }^{\circ} \mathrm{C}\right]}\end{array}$} & \multirow{2}{*}{$\begin{array}{l}T \\
{[\mathrm{~h}]}\end{array}$} & \multirow{2}{*}{$\begin{array}{l}p \\
{[\mathrm{MPa}]}\end{array}$} & \multirow{2}{*}{$\begin{array}{l}\text { Conv. } \\
{[\%]}\end{array}$} & \multicolumn{5}{|c|}{ Selectivity $^{[f]}[\%]$} & \multirow{2}{*}{$\begin{array}{c}\text { PC } \\
\text { Yield }^{[f]}[\%]\end{array}$} \\
\hline & & & & & & PC & 1 & 2 & 3 & others & \\
\hline 1 & $1 S^{[b]}$ & 140 & 2 & 2 & 100 & 84.6 & 10.6 & 1.6 & 2.1 & 1.1 & 84.6 \\
\hline 2 & $1 \mathrm{G} / 1 \mathrm{~S}^{[\mathrm{c}]}$ & 140 & 2 & 2 & 100 & 84.8 & 9.5 & 2.4 & 2.0 & 1.3 & 84.8 \\
\hline 3 & $1 G / 1 S / 1 H^{[d]}$ & 140 & 2 & 2 & 100 & 86.3 & 8.9 & 2.3 & 1.6 & 0.9 & 86.3 \\
\hline 4 & PC from pine $e^{[e]}$ & 150 & 3 & 3 & 100 & 76.5 & 17.6 & - & - & 5.9 & 76.5 \\
\hline 5 & PC from poplar ${ }^{[e]}$ & 150 & 3 & 3 & 100 & 75.1 & 18.5 & - & - & 6.4 & 75.1 \\
\hline 6 & PC from beech ${ }^{[e]}$ & 150 & 3 & 3 & 100 & 74.2 & 19.2 & - & - & 6.6 & 73.3 \\
\hline
\end{tabular}

[a] $1 \mathrm{~g}$ wet Raney nickel, $15 \mathrm{~mL}$ isopropanol, $20 \mathrm{mg}$ dodecane as an internal standard; [b] $1 \mathrm{mmol}$ (0.212 g) 1S; [c] $0.55 \mathrm{mmol}$ (0.100 g) 1G, $0.47 \mathrm{mmol}(0.100 \mathrm{~g}) \mathbf{1 S}$; [d] $0.27 \mathrm{mmol}(0.050 \mathrm{~g}) \mathbf{1 G}, 0.23 \mathrm{mmol}(0.050 \mathrm{~g}) \mathbf{1 S}, 0.65 \mathrm{mmol}(0.100 \mathrm{~g}) \mathbf{1 H}$; [e] $2 \mathrm{~g}$ Lignocellulose; [f] Selectivity and yield values were determined using dodecane as internal standard; PC was obtained as a mixture of isomers (cis : trans $=1: 2)$;

\section{Catalytic funneling of crude RCF mixtures}

Next, we applied the developed Ni-based method for the chemo-catalytic funneling of the bio-oil obtained through RCF of beech lignocellulose (Supplementary Section 2.5). Treating $2 \mathrm{~g}$ of beech wood over $\mathrm{Cu}_{20} \mathrm{PMO}$ using 40 bar $\mathrm{H}_{2}$ at $180{ }^{\circ} \mathrm{C}$ gave crude bio-oil (Fig.3, Crude 1) rich in the desired phenolic monomers $1 \mathrm{G}$ (31.3 mg) and $1 \mathbf{S}$ (65.2 mg). Further in-depth analysis by 2D-HSQC (Fig. S29), GC-FID (Fig. S27 b) and GPC (Fig. S28) revealed the presence of additional monomers $2 \mathrm{~S}(21.8 \mathrm{mg}), \mathbf{2} \mathbf{G}(5.2 \mathrm{mg}), \mathbf{3 S}(4.6 \mathrm{mg})$ as well as lignin dimers (Fig. S27 a), oligomers and sugar residues (Fig. S28, S29). Initial attempts to directly subject Crude 1 to further catalytic treatment were unsuccessful, likely due to catalyst deactivation. Therefore, a simple fractionation protocol was implemented to get rid of residual lignin oligomers, sugars and small amounts of organic acids, that may be detrimental for the catalysis, as earlier reported ${ }^{46}$. Gratifyingly, after this treatment, the - still multicomponent - Fraction 3 was smoothly converted to a mixture of aliphatic alcohols rich in PC (52.4 mg, 73.3\%) and $\mathbf{1}(16.3 \mathrm{mg}$ ) (Fig. 3), originating from $\mathbf{1 G}$ and $\mathbf{1 S}$, which represents $13.9 \mathrm{wt} \%$ yield based on lignin, an efficiency of $56.3 \%$ (given that theoretical maximum yield is $24.7 \mathrm{wt} \%$ (Supplementary Note 1). Furthermore, compounds 2S, 2G, 3S, and 3G also contained in Fraction $\mathbf{3}$ in smaller amounts, were converted to alcohols $\mathbf{2}$ (5.7 $\mathrm{mg}$ ) and 3 (11 mg), while aliphatic dimers and oligomers (totally approximately $40 \mathrm{mg}$ ) were also formed, and these accounted for less than $28.3 \mathrm{wt} \%$ of the defunctionalized and hydrogenated product mixture (Fig. 27 a). PC was obtained by column chromatography from the aliphatic product mixture in an excellent $11.7 \mathrm{wt} \%$ isolated yield (Supplementary Section 2.5).

To evaluate the generality of the method, pine and poplar lignocellulose ( $2 \mathrm{~g}$ each) were also subjected to RCF to give crude bio-oil, resulting in $\mathbf{1 G}$ from pine wood in $7.5 \mathrm{wt} \%$ yield ( $88.0 \%$ selectivity), as well as a mixture of 1 G (30 \% selectivity) and $\mathbf{1 S}$ ( $46.1 \%$ selectivity) from poplar wood in $28.2 \mathrm{wt} \%$ combined yield as summarized in Table S8. After applying the developed fractionation protocol, catalytic funneling of these RCF oils (see also Table S8) gave $4.6 \mathrm{wt} \%$ yield to PC (76.5\% selectivity) for pine and $15.5 \mathrm{wt} \%$ yield of PC (75.1\% selectivity) for poplar lignocellulose (Table 1 - Entry 4 and 5, Fig. 3).

Considering our strategy, where PC is obtained from lignin through RCF and catalytic funneling, a portion of the residual cellulose may be utilized for the production of FDCA or TPA by applying methods that are already established (Supplementary Section $\mathbf{1 . 6}$ for more details), thereby giving fully wood-based PET analogues. Therefore, we have selected methyl esters of aromatic diacids TPA and FDCA for co-polymerization with PC (Details on polymer synthesis see Supplementary section $\mathbf{3}$ ). Thus, the methyl ester of TPA was co-polymerized with PC using $\mathrm{Zn}(\mathrm{OAc})_{2}$ as catalyst to result in poly (PC, TPA) in up to $75.0 \%$ yield (Table 2, Entry 4), while copolymerization of PC with the methyl ester of FDCA using Titanium (IV) butoxide (TBT) as catalyst gave poly (PC, FDCA) in excellent, up to $92.3 \%$ yield (Table 2, Entry 2). All prepared polymers displayed a molecular weight range of $20-50 \mathrm{~kg} \cdot \mathrm{mol}^{-1}$ (Table 2). Selected samples of poly (PC, TPA) and poly (PC, FDCA) were also subjected to a purification protocol ${ }^{47}$, which further enhanced their $M w$ to $50 \mathrm{~kg} \cdot \mathrm{mol}^{-1}$ (Table 2, Entries 3, 6, Fig. S55, S65) 


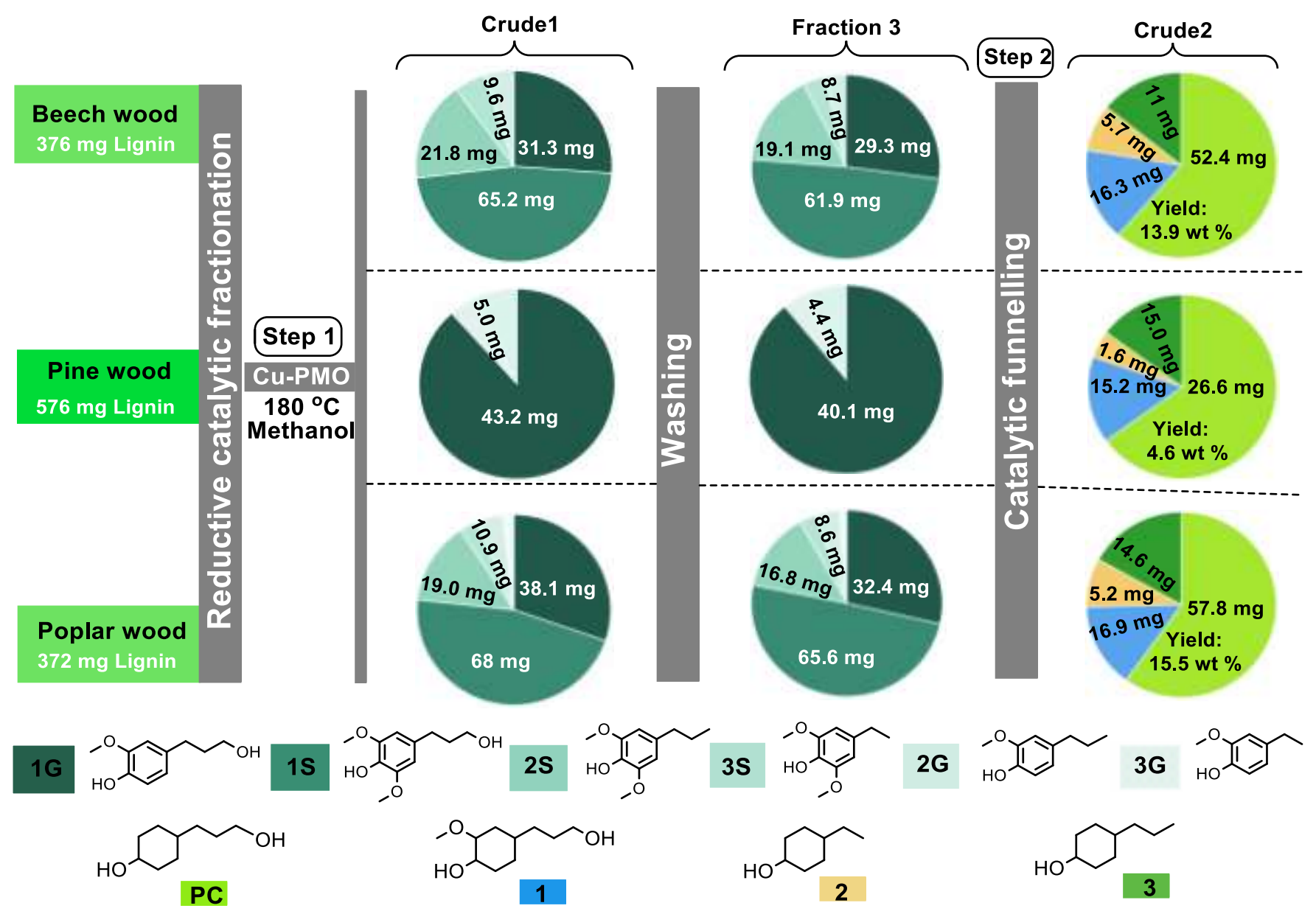

Fig. 3 A catalytic reaction protocol toward the production of PC directly from crude RCF mixture of beech, pine and poplar lignocellulose; Step 1: RCF of beech, pine and poplar wood over $\mathrm{Cu}_{20} \mathrm{PMO}$ catalyst to give Crude 1. Crude 1 was subjected to fractionation with EtOAC and washing with saturated $\mathrm{NaHCO}_{3}$ and brine to give Fraction 3; Step 2: Catalytic funneling of Fraction 3 to PC and other cyclohexane derivatives over Raney nickel/isopropanol. Yield was given based on lignin content. On this figure only the volatile, monomeric products are displayed. More quantification, analysis and characterization details can be found in Supplementary section 2.5 .

\section{Synthesis of novel, PET analogues using lignin derived model PC compound}

Table 2. Molecular-weight distributions and thermal properties data for synthesized polymers ${ }^{[a]}$

\begin{tabular}{|c|c|c|c|c|c|c|c|c|c|c|}
\hline Entry & Substrate & Catalyst & $\begin{array}{l}\text { Time } \\
\text { (h) }\end{array}$ & $\begin{array}{l}\text { Yield }^{[\mathrm{d}]} \\
{[\%]}\end{array}$ & $\begin{array}{l}M w^{[\mathrm{e}]} \\
{\left[\mathrm{g} \cdot \mathrm{mol}^{-1}\right]}\end{array}$ & $\begin{array}{l}\mathrm{Mn}^{[\mathrm{e}]} \\
{\left[\mathrm{g} \cdot \mathrm{mol}^{-1}\right]}\end{array}$ & $\bigoplus^{[\mathrm{e}]}$ & $\begin{array}{l}T_{5 \%}{ }^{[\mathrm{f}]} \\
{\left[{ }^{\circ} \mathrm{C}\right]}\end{array}$ & $\begin{array}{l}T_{90 \%}{ }^{[f]} \\
{\left[{ }^{\circ} \mathrm{C}\right]}\end{array}$ & $\begin{array}{l}T_{g}^{[g]} \\
{\left[{ }^{\circ} \mathrm{C}\right]}\end{array}$ \\
\hline 1 & Poly (PC, FDCA) & TBT & 1 & 88.0 & 33387 & 15601 & 2.14 & 280 & 347 & 72.7 \\
\hline 2 & Poly (PC, FDCA) & TBT & 3 & 92.3 & 33544 & 12035 & 2.79 & 320 & 371 & 71.4 \\
\hline 3 & Poly (PC, FDCA) ${ }^{[b]}$ & TBT & 3 & 68.4 & 50676 & 12553 & 4.03 & 278 & 335 & 75.3 \\
\hline 4 & Poly (PC, TPA) & $\mathrm{Zn}(\mathrm{OAC})_{2}$ & 1 & 75.2 & 22910 & 11780 & 1.94 & 320 & 373 & 75.8 \\
\hline 5 & Poly (PC, TPA) & $\mathrm{Zn}(\mathrm{OAC})_{2}$ & 3 & 72.1 & 31789 & 14163 & 2.24 & 329 & 381 & 80.7 \\
\hline 6 & Poly (PC, TPA) ${ }^{[b]}$ & $\mathrm{Zn}(\mathrm{OAC})_{2}$ & 3 & 50.8 & 46364 & 14081 & 3.29 & 319 & 378 & 86.9 \\
\hline 7 & Poly (PC cis, TPA) & $\mathrm{Zn}(\mathrm{OAC})_{2}$ & 1 & 84.0 & 21210 & 9064 & 2.34 & 319 & 367 & 72.2 \\
\hline 8 & Poly (PC trans,, $\mathrm{TPA})$ & $\mathrm{Zn}(\mathrm{OAC})_{2}$ & 1 & 53.2 & 16869 & 8188 & 2.06 & 313 & 376 & 50.9 \\
\hline 9 & Poly $(P C, 1, T P A)^{[c]}$ & $\mathrm{Zn}(\mathrm{OAC})_{2}$ & 1 & 61.8 & 19274 & 6202 & 3.11 & 318 & 378 & 79.7 \\
\hline 10 & Poly (PC, 1, FDCA) ${ }^{[c]}$ & TBT & 1 & 79.1 & 20840 & 6240 & 3.34 & 306 & 388 & 72.2 \\
\hline
\end{tabular}

[a] $3.4 \mathrm{mmol}$ diol, $3.4 \mathrm{mmol}$ DMFD/DMTA, $1 \mathrm{~mol} \%$ catalyst, $190{ }^{\circ} \mathrm{C} \mathrm{N} / 1 \mathrm{~h}, 230^{\circ} \mathrm{C}$ vacuum $1 \mathrm{mPa}$; [b] Poly (PC, TPA) and poly (PC, FDCA) at vacuum for $3 \mathrm{~h}$ were subjected to purification by dissolving precipitation method; [c] Copolymerization of crude mixture of diols PC /1 (with a purity of $95 \%$ ) obtained from catalytic funneling of model equal molar of 1G/1S mixture with DMFD and DMTA (See Supplementary section 3.4); [d] Yield (\%) = weight of collected product /weight of theoretical product $\times 100 \%$; [e] Molecular weight distribution by GPC; [f] $T_{5 \%}$ and $T_{90 \%}$ were determined by TGA characterization; [g] $T_{g}$ determined by DSC characterization. 
Structural characterization: The obtained PET analogues were structurally characterized by ${ }^{1} \mathrm{H},{ }^{13} \mathrm{C}$ NMR, 2D NMR (Fig. S35-S45) and FT-IR (Fig. S67) as extensively discussed in Supplementary Section 3.1 and briefly below. Featuring both an aliphatic primary and secondary alcohol moiety, diol PC is asymmetric in nature and this leads to different reactivity and unit connectivity when forming an ester linkage with diacids at each end of the molecule, hence forming three distinct diads, namely head-to-tail (H-T), head-to-head (H-H), and tail-to-tail (T-T) (Fig. 4A). We have first assigned the main-chain sequence of poly (PC, TPA), where PC is a mixture of cis and trans isomers (ratio of $1: 2$ ), by ${ }^{1} \mathrm{H},{ }^{13} \mathrm{C}$ NMR and $2 \mathrm{D}$ HSQC spectroscopy (Fig. 4C) (for 2D HMBC see Fig. S45). The polymer diad structure was established by ${ }^{13} \mathrm{C}$ NMR (Fig. 4B, Fig. S44) analysis that displayed three distinguishable groups of carbonyl signals (C8). Based on related literature data, the high field signals of $\mathbf{C 8}$ at 165.24 ppm (C8 cis) and 165.42 ppm (C8 trans) were assigned to $\mathbf{H}-\mathbf{H}$ type ${ }^{48}$, the low field $\mathbf{C} 8$ signals (cis and trans overlapped) at 166.05 ppm to T-T type structure ${ }^{49}$, and the signals in-between (165.28, 165.48, and $165.97 \mathrm{ppm}$ ) to mixed (H-T, T-H) type connectivity units. The signal assignment was further confirmed by $2 \mathrm{D}^{1} \mathrm{H}-{ }^{13} \mathrm{C} \mathrm{HMBC}$ (Fig. S45), where protons H1, correlating with C8 at $165.2-165.5 \mathrm{ppm}$ and at $165.95-166.05 \mathrm{ppm}$, respectively displayed a $\mathbf{H}$ type bonding, while proton $\mathbf{H 7}$ correlating with $\mathbf{C 8}$ at 165.9-166.1 ppm was assigned to a $\mathbf{T}$ type bonding. The proposed structural assignment was further supported by comparing the spectral data of poly (PC,

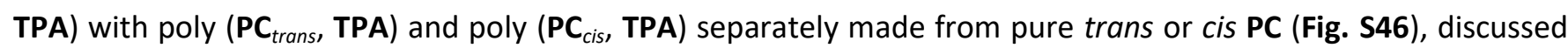
in detail in the Supplementary Section 3.1. The signals of $\mathbf{C 8}$ were assigned according to T-T, T-H and $\mathbf{H}-\mathbf{H}$ type of diads, which displayed a random distribution: $[\mathrm{H}-\mathrm{H}]=[\mathrm{T}-\mathrm{T}]=0.25$ and $[\mathrm{H}-\mathrm{T}]=0.50$, as quantified by integration of quantitative ${ }^{13} \mathrm{C}$ NMR spectrum (Fig. S44). The structural analysis of the polymer poly (PC, FDCA) is discussed in detail in the Supplementary Section 3.2, similarly to the poly (PC, TPA), it is a random type polymer.

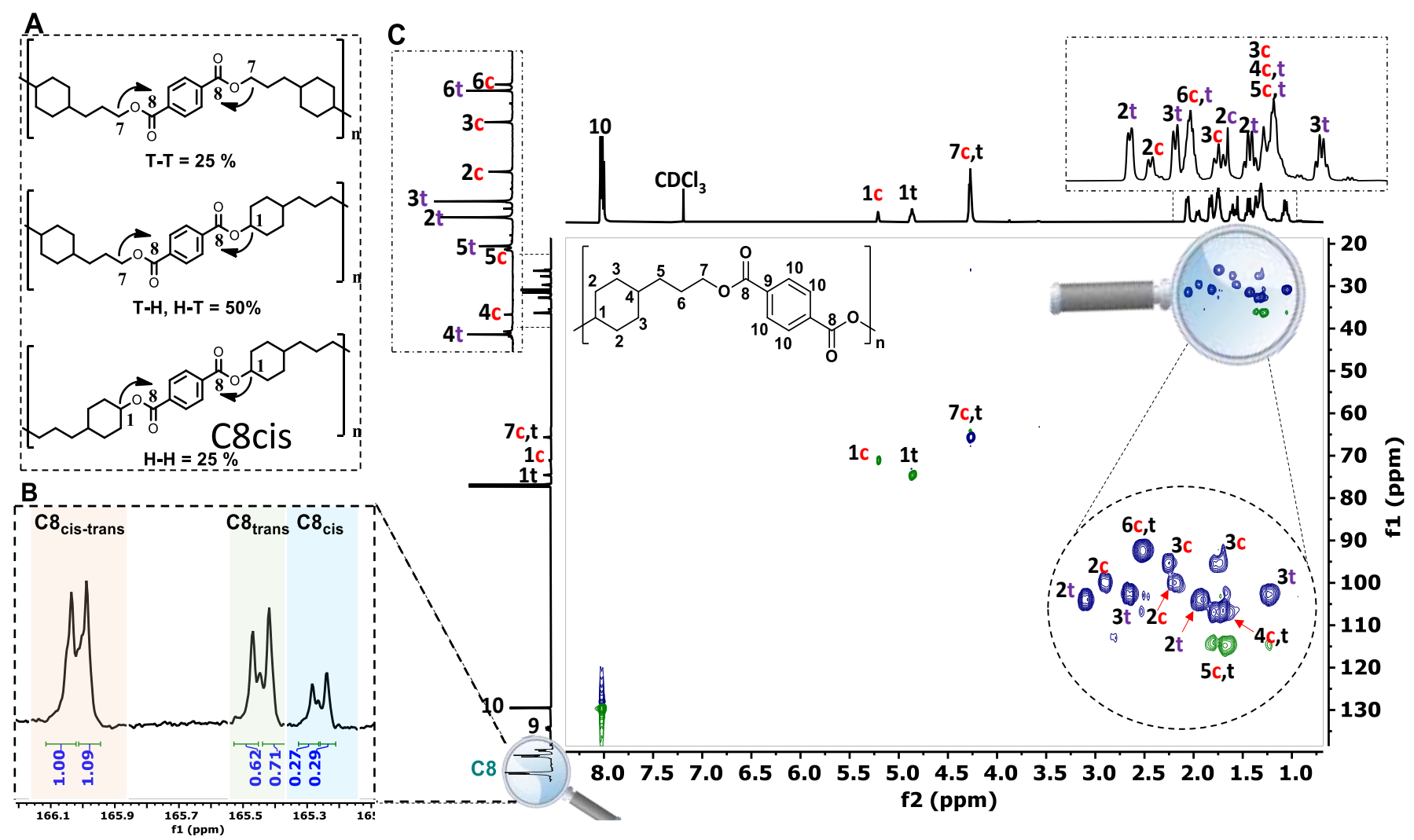

Fig. 4. Structural characterization of poly (PC, TPA) based on NMR spectroscopy. A) Proposed unit connectivity of poly (PC, TPA) copolymerized using PC (1:2 mixture of cis and trans isomers) and DMTA by forming three distinct diads, namely head-to-tail (H-T), head-to-head (H-H), and tail-to-tail (T-T); B) The identification and quantification of carbonyl carbon signals (C8) of poly (PC, TPA). Assignment of chemical shifts to the various connectivity units, namely cis, trans and cis-trans; C) 2D-HSQC characterization for the main-chain sequence of poly (PC, TPA). 
Thermal analysis: Overall, the favorable thermal properties of poly (PC, TPA) and poly (PC, FDCA) indicate significant potential for the use of these polymers in applications similar to the application are of PET or as a replacement. Gratifyingly, with glass transition temperature $\left(T_{g}\right)$ between $70-90^{\circ} \mathrm{C}$, both poly $(\mathrm{PC}, \mathrm{TPA})$ and poly (PC, FDCA) (Table 2, Entries 1-6) showed a thermal behavior comparable or better to that of commercial PET $\left(T_{g}=\right.$ $\left.67-80^{\circ} \mathrm{C}\right)^{50}$. Furthermore, these polymers also showed good thermal stability with decomposition temperature $T_{5 \%}$ $=329^{\circ} \mathrm{C}$ and $T_{5 \%}=319{ }^{\circ} \mathrm{C}$ under $\mathrm{N}_{2}$, albeit lower than that of commercial PET $\left(410^{\circ} \mathrm{C}\right)$.

The physical and thermal properties of poly ( $\left.\mathbf{P C}_{\text {ciss }}, \mathbf{T P A}\right)$ and poly $\left(\mathbf{P C}_{\text {trans, }}, \mathbf{T P A}\right)$ were also compared with that of the synthesized poly (PC, TPA). While poly ( PC $_{c i s}$, TPA) was obtained in $84 \%$ yield, only $53 \%$ yield was reached for poly ( $\mathbf{P C}$ trans, $\mathbf{T P A}$ ) indicating somewhat higher reactivity of the cis $\mathbf{P C}$ isomer in the polycondensation reaction. Interestingly, the molecular weight distribution of poly (PC, TPA) was higher than either of the polymers obtained from the pure isomers $\mathbf{P} \mathbf{C}_{\text {cis }}$ or $\mathbf{P C}$ trans. $\mathrm{A}$ better heat resistance $\left(T_{g}\right.$ value of $\left.75.8^{\circ} \mathrm{C}\right)$ was obtained for poly (PC, TPA) synthesized from a mixture of cis and trans PC isomers, while different $T_{g}$ values $\left(72.2^{\circ} \mathrm{C}\right.$ versus $\left.50.9^{\circ} \mathrm{C}\right)$ were observed for the pure $\mathbf{P C}_{\text {cis }}$ and $\mathbf{P C}$ trans analogues (Table 2, Entries 7, 8). The $T_{5 \%}$ values were in the range of 310-320 ${ }^{\circ} \mathrm{C}$ (Table 2, Entries 7, 8) for all poly (PC, TPA) variants. Gratifyingly, the obtained thermal characteristics demonstrate that there is no need for separation of the mixture of cis and trans isomers of PC obtained by catalytic funneling prior to polymerization.

Next, polyesters from the aliphatic alcohol mixture of PC (78 \%) and 1 (17\%) obtained from catalytic funneling of a standard equimolar mixture of $\mathbf{1 G}$ and $1 \mathrm{~S}$ were prepared (Supplementary Section 3.4). The molecular weights of the corresponding poly (PC, 1, TPA) $\left(M w=19.4 \mathrm{~kg} \cdot \mathrm{mol}^{-1}, \Theta=3.11\right)$ and poly (PC, 1, FDCA) $\left(M w=20.8 \mathrm{~kg} \cdot \mathrm{mol}^{-1}, \theta=3.34\right)$ were somewhat lower, than the polyesters prepared from pure PC (Table 2 Entries 9, 10 versus Entries 1, 4), while the $T_{5 \%}$ values were comparable, albeit here polycondensation was performed for 1 hour under vacuum instead of 3 hours.

\section{A comprehensive biorefinery strategy for the conversion of beech wood to PET analogues and complementary products}

To show scalability of our method in a comprehensive biorefinery context, we demonstrated access to PET analogues and complementary product streams such as light and heavy hydrocarbons as shown in Fig. $\mathbf{5}$ (see also Supplementary Section 3.5). Applying the previously developed two-step catalytic sequence (Cu20$\mathrm{PMO} /$ methanol and Raney $\mathrm{Ni} /$ isopropanol) using $10 \mathrm{~g}$ beech lignocellulose, crude bio-oil (Fraction 3) was obtained that was subjected to careful fractional distillation $\left(1 \mathrm{mpa}, 100-120^{\circ} \mathrm{C}\right)$ to deliver three distinct Subfractions (A, B, and C), consisting of three specific product streams: 4-alkyl cyclohexanols (A), cyclohexane-diol derivatives $\mathbf{P C}$ and $\mathbf{1}$ (B), and higher boiling point dimers and oligomers (C).

Considering raw woody biomass as substrate, the number and difficulty of reaction and product isolation/purification steps will largely influence the overall feasibility of a biorefinery strategy. Here we demonstrate that the polymer building block PC can be obtained in a straightforward manner and high yield from raw biomass. In fact, Sub-fraction B (Fig. S76) obtained directly upon fractional distillation from Fraction 3, only consisted of diol PC and $\mathbf{1}$ in high purity (>99\%), representing 15.3 wt \% yield based on lignin content and could be directly subjected to copolymerization with methyl ester of FDCA to give poly (PC, 1, FDCA), that showed excellent and comparable molecular weight $\left(\mathrm{Mw}=27.5 \mathrm{~kg} \cdot \mathrm{mol}^{-1}, \Theta=2.36\right)$ and thermal properties $\left(T_{g}=73.5^{\circ} \mathrm{C}\right.$ and $T_{5 \%}=294^{\circ} \mathrm{C}$ ), as poly (PC, FDCA) that was prepared using pure PC (for characterizations by ${ }^{1} \mathrm{H}$ NMR (Fig. S77), GPC (Fig. S78), TGA (Fig. S80) and DSC (Fig. S79).

Given that Sub-fractions $\mathbf{A}$ and $\mathbf{C}$ consisted of more components, we aimed for extensive hydrodeoxygenation (HDO) to alkanes over Raney nickel and HZSM-5 co-catalyst at $220^{\circ} \mathrm{C}$, using cyclohexane as solvent. Thus, Sub-fraction A was converted to gasoline range C7-C9 cyclic hydrocarbons, a mixture of 4-methyl,4-ethyl-, and 4-propyl-cyclohexane (Fig. S75). The heavier Sub-fraction C was characterized by ${ }^{1} \mathrm{H}$ NMR (Fig. S82), 2D-HSQC (Fig. S84) and GC-FID (Fig. S81), which confirmed the presence of oxygenated aliphatic dimers and 
oligomers. These were obtained from the extensive hydrogenation of the lignin-derived dimers and smaller oligomers present in the crude Fraction $\mathbf{3}$, originating from the $\boldsymbol{\beta}-\mathbf{1}, \boldsymbol{\beta}-\mathbf{5}, \boldsymbol{\beta}-\boldsymbol{\beta}$ and $\mathbf{5 - 5}$ linked aromatic dimer units present in hardwood ${ }^{50,51}$. Analysis of the products obtained upon HDO of Sub-fraction $\mathrm{C}$ by ${ }^{1} \mathrm{H}$, DEPT NMR (Fig. S82, S83), 2D-HSQC (Fig. S85) and GC-FID (Fig. S81), revealed successful removal of aliphatic -OH as well as -OMe groups to deliver higher $\mathrm{Mw}$ cyclic liquid hydrocarbons (only signals at 0.5-2.0 ppm observed). Further GC-MS analysis confirmed the presence of predominantly bicyclic hydrocarbons and small amount of tricyclic and polycyclic hydrocarbons (Fig. S81). These were quantified by the ECN method. Overall, from $50 \mathrm{mg}$ Sub Fraction C, $18.6 \mathrm{mg}$ crude alkane product was obtained, consisting of predominately $1.2 \mathrm{mg} \mathrm{H}_{\beta-1}, 2.3 \mathrm{mg} \mathrm{H}_{\beta-5}, 5.3 \mathrm{mg} \mathrm{H}_{\beta-\beta, \beta}, 0.8$ $\mathrm{mg} \mathbf{H}_{5-5}$, and c.a. $3.1 \mathrm{mg}$ unidentified dimers or oligomers.

Overall, this strategy leads to an excellent valorization of beech lignocellulose by converting the lignin component to gasoline (C6-C8 hydrocarbons), high energy density alkane jet fuel (C14-C17 hydrocarbons) and PET analogues, accounting for an overall $36.2 \%$ lignin utilization based on isolated yields (Supplementary Note 2). At the same time, the cellulose residues upon RCF can be used to cover the FDCA and TPA necessary for the polymer synthesis, and any surplus could be converted to bioethanol ${ }^{52}$, or $\mathbf{E G}^{22,23}$ while hemicellulose could be converted to valuable $\mathbf{C 5}$ platform chemicals or $\mathbf{E G}^{24}$ (for calculations see Supplementary section 1.6).

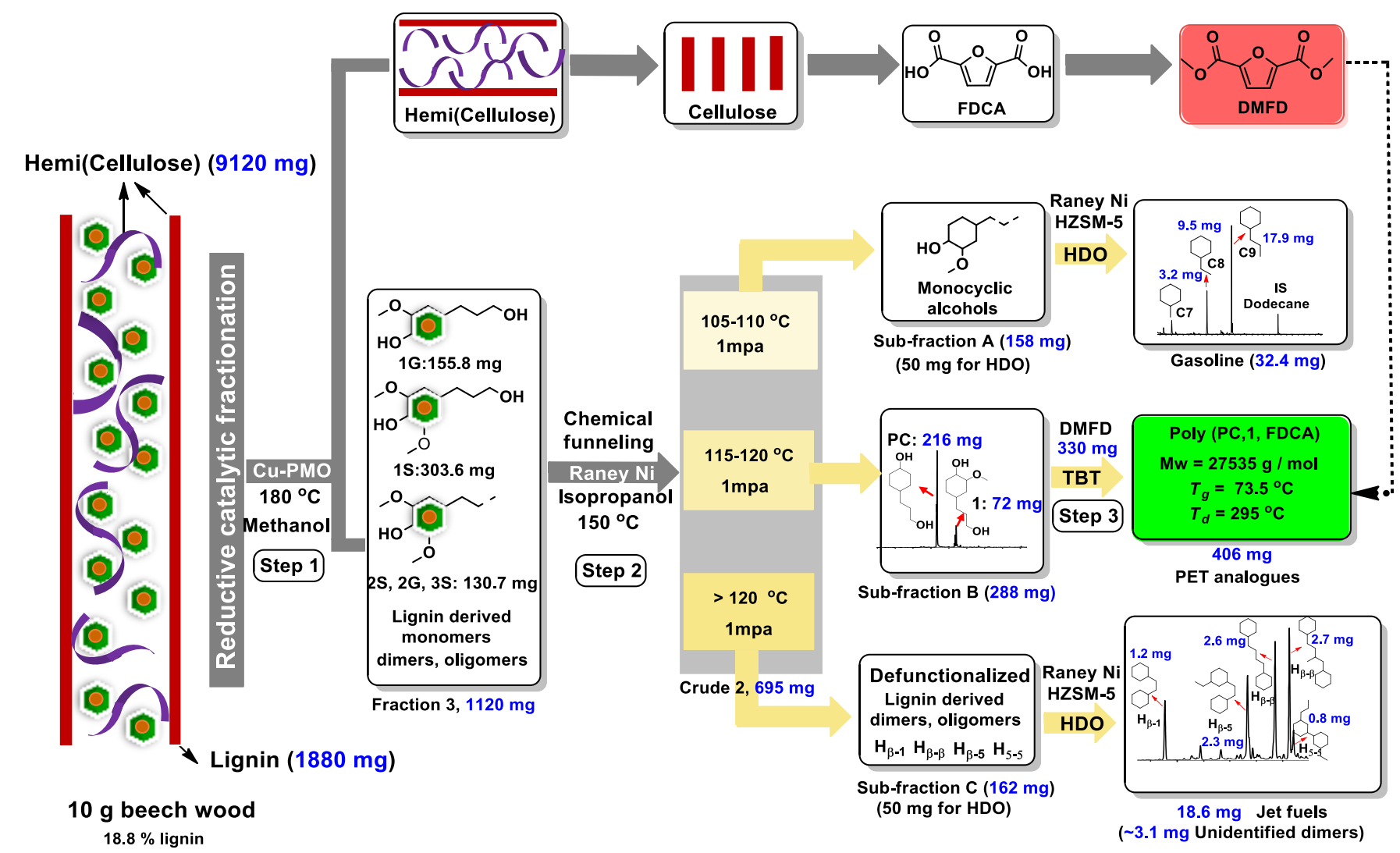

Fig. 5 Comprehensive catalytic protocol for beech wood biorefinery for producing PET analogues and fuels. Step 1: RCF of beech wood over Cu-PMO catalyst ( $10 \mathrm{~g}$ beech wood, $2 \mathrm{~g}$ Cu-PMO catalyst, $120 \mathrm{~mL}$ methanol, 40 bar $\mathrm{H}_{2}, 180^{\circ} \mathrm{C}, 18 \mathrm{~h}$ ) gives crude lignin oil and residual carbohydrates; removal of impurities to give Fraction 3; Step 2: Catalytic funneling of Fraction 3 (1120 mg Fraction 3, $2 \mathrm{~g}$ Raney nickel catalyst, $30 \mathrm{~mL}$ isopropanol, $150{ }^{\circ} \mathrm{C}, 12 \mathrm{~h}$ ) to a mixture of aliphatic alcohols Crude 2 which is purified by distillation under $1 \mathrm{mpa}$ at $\left(100-120^{\circ} \mathrm{C}\right)$ to deliver three Sub-fractions $\left(\mathbf{A}\left(100-105^{\circ} \mathrm{C}\right), \mathbf{B}\left(115-120^{\circ} \mathrm{C}\right)\right.$ and $\mathbf{C}\left(>120^{\circ} \mathrm{C}\right)$ ). PET analogue synthesis: Reaction conditions (288 mg Sub-fraction B, $330 \mathrm{mg}$ DMFD $(1.79 \mathrm{mmol}), 1 \mathrm{~mol} \%$ TBT catalyst, $190^{\circ} \mathrm{C} \mathrm{N}$ for $1 \mathrm{~h}, 230^{\circ} \mathrm{C}$ under vacuum for $3 \mathrm{~h}$ ), Copolymerization of Sub-fraction B with DMFD yields poly (PC, 1, FDCA); Hydrodeoxygenation: Reaction conditions ( $50 \mathrm{mg}$ Fraction A or C, $200 \mathrm{mg}$ Raney Ni, $100 \mathrm{mg}$ activated H-ZSM-5 cocatalyst, $20 \mathrm{~mL}$ cyclohexanol, $220^{\circ} \mathrm{C}, 30 \mathrm{bar}_{2}, 4-6 \mathrm{~h}$ ); $\mathrm{HDO}$ of Sub-fraction A gives $\mathrm{C6}, \mathrm{C7}$, and $\mathbf{C 8}$ cyclic alkanes. $\mathrm{HDO}$ of Sub- 
fraction $\mathbf{C}$ gives high density cyclic alkanes. The hydrocarbons were quantified using the response of the flame-ionization detector (FID) and the response factors were estimated by Effective Carbon Number method (ECN).

The recyclability of poly (PC, TPA) was evaluated by subjecting the material to alcoholysis using methanol, ethanol, 1-propanol, or $n$-butanol at $180{ }^{\circ} \mathrm{C}$ for $4 \mathrm{~h}$, without any additives. The best results were obtained in methanol at $180{ }^{\circ} \mathrm{C}$ where $80 \%$ of PC and $85 \%$ for the methyl ester of TPA (DMTA) could be recovered. Lower yield (<40\%) of PC and the corresponding ethyl and propyl terephthalates were obtained in ethanol and 1propanol (Fig. S87A) and no reactivity was found in $n$-butanol. Gratifyingly, methanolysis of poly (PC, TPA) at $190{ }^{\circ} \mathrm{C}$ resulted in $90 \%$ and $92 \%$ isolated yield of PC and DMTA obtained (Fig. S87B).

With the optimized conditions in hand, this polymer was subjected to recycling (Supplementary Section 4.2). As shown in Fig. 6, poly (PC, TPA) was first synthesized and molded for possible applications. Then the produced material was subjected to methanolysis under $190^{\circ} \mathrm{C}$ to give a crude mixture of PC and DMTA, characterized by ${ }^{1} \mathrm{H}-\mathrm{NMR}$ (Fig. S90) and GC-FID (Fig. S89). Next, the crude mixture was repolymerized under the original conditions $\left(1 \mathrm{~mol} \% \mathrm{Zn}(\mathrm{OAc})_{2}\right.$ catalyst, $190{ }^{\circ} \mathrm{C} \mathrm{N}_{2} / 1 \mathrm{~h}, 230^{\circ} \mathrm{C}$ under vacuum $(1 \mathrm{mPa} / 1 \mathrm{~h})$ to regain poly (PC, TPA), which showed structural and thermal properties $\left(\mathrm{Mw}=16 \mathrm{~kg} \cdot \mathrm{mol}^{-1}, T_{g}=72{ }^{\circ} \mathrm{C}, T_{5 \%}=319{ }^{\circ} \mathrm{C}\right)$ similar to the virgin polymer (Fig. S91, Fig. S92 and Fig. S93). These experiments demonstrate the feasibility of our novel PET analogues for the circular economy.

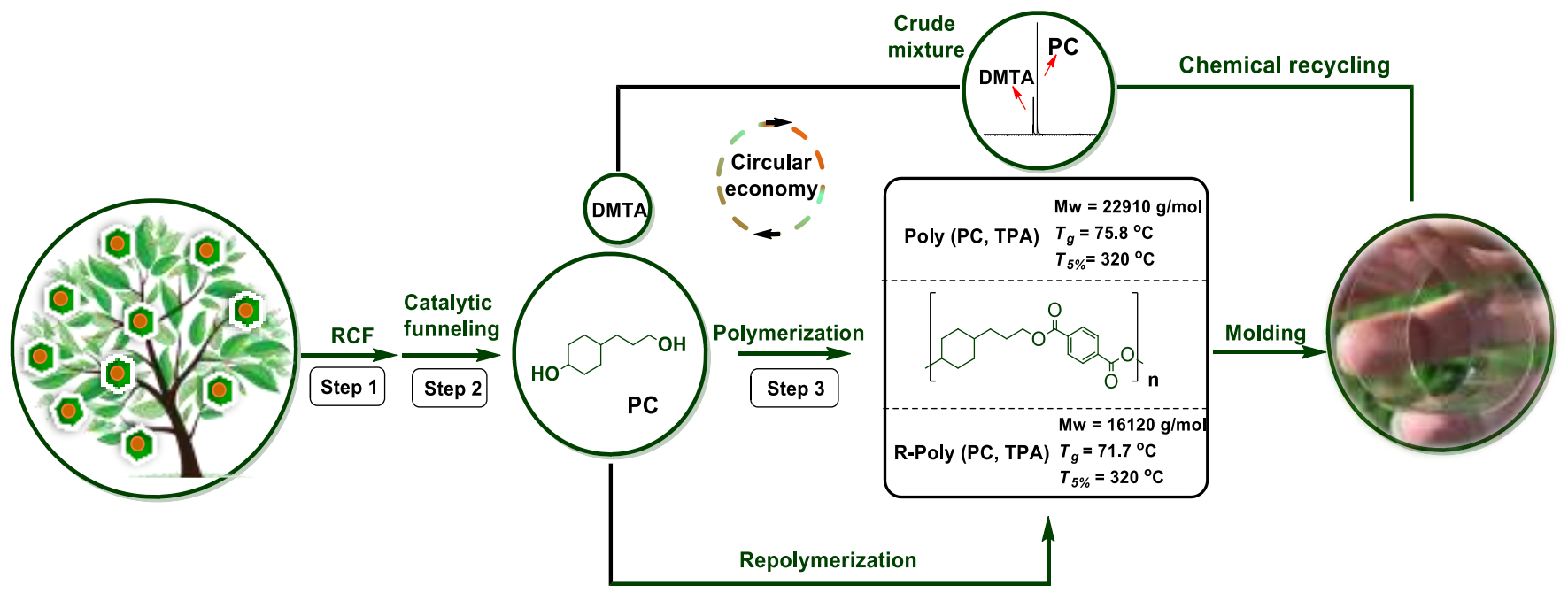

Fig. 6 A circular economy strategy for plastic recycling. Step 1: RCF of lignocellulose over previously developed Cu-PMO catalyst; Step 2: Catalytic funneling of RCF crude mixture over Raney Nickel catalyst using isopropanol as solvent.; Step 3: The co-polymerization of PC with DMTA to give poly (PC, TPA) using $\mathrm{Zn}(\mathrm{OAC})_{2}$ catalyst; One-pot methanolysis of poly (PC, TPA) to recycle monomers PC and DMTA; The crude mixture from depolymerized poly (PC, TPA) was repolymerized using $\mathrm{Zn}(\mathrm{OAC})_{2}$ catalyst to give R-poly (PC, TPA).

\section{Conclusions}

\section{Conclusions}

Reductive catalytic fractionation (RCF) is a prominent technique, able to convert raw lignocellulosic biomass into phenolic monomers, aromatic $\mathrm{C}-\mathrm{C}$ bonded dimers, oligomers, and high quality (hemi)cellulose streams. This work demonstrates an RCF-based biorefinery approach to produce PET-analogues made entirely of wood, together with gasoline and jet-range fuels and fuel additives. Central to the strategy is the catalytic funneling of aromatic monophenols $1 \mathbf{G}$ and $1 S$ into 4-(3-hydroxypropyl) cyclohexan-1-ol (PC) by highly selective Ni-catalyzed hydrogenation/defunctionalization. When applying this method to the complex bio-oil obtained from native lignin, a mixture of PC and other cyclic and bicyclic aliphatic alcohols are obtained in the same pot, which are 
separated by fractional distillation into three distinct cuts based on their boiling point. Thus PC is isolated as single compound in high purity and is co-polymerized with cellulose-derived FDCA and PTA while the lighter and heavier fractions can be further processed by HDO to petrol and jet-fuel range alkanes, respectively. Overall, an estimated lignin utilization efficiency of $36.2 \%$ can be reached based on isolated product yields, which may be further improved by adjusting the RCF step at the front end of the process. In fact, by improving delignification, while maintaining high yield and selectivity of $\mathbf{1 G}$ and $\mathbf{1 S}$, a near-theoretical yield of PC may be potentially reached. The Ni-catalyzed funneling strategy developed here can be universally used for any bio-oil obtained from RCF ${ }^{[58]}$ or other prominent cutting-edge depolymerization efforts ${ }^{[59]}$. Calculations based on selected literature routes show, that the cellulose residue is sufficient to supply for the quantity of aromatic diacids (FDCA or PTA) needed for the co-polymerization; besides any surplus of carbohydrates could be converted to ethylene glycol, which may further provide diol equivalents to be added to the polyesters, and achieve full lignocellulose utilization.

The approach presented, consisting of two distinct catalytic steps, one extraction and one distillation, enables the smooth processing of complex raw biomass feed into a single pure diol PC, readily incorporated into the fully biobased polyesters poly (PC, TPA) and poly (PC, FDCA), which display molecular weight range and thermal properties comparable or better than conventional PET, and can be recycled into the virgin monomers. The competitive physical and chemical properties of the polymers, in addition to the straightforward method of producing PC that avoids any extensive purification effort or column chromatography, makes this process feasible for future upscaling efforts and the PET analogues are promising candidates for the circular economy.

\section{Experimental}

\section{Materials and reagents}

Pine lignocellulose was purchased from Bemap Houtmeel B.V. Poplar and beech lignocellulose were obtained from a local wood shop (Dikhout, Groningen, the Netherlands). Chemicals were used as received, unless otherwise specified. Raney nickel 4200, Palladium on carbon, Nickel on carbon, Ruthenium on carbon, $65 \%$ $\mathrm{Ni} / \mathrm{SiO}_{2}-\mathrm{Al}_{2} \mathrm{O}_{3}$, Titanium (IV) butoxide (TBT), $\mathrm{Zn}(\mathrm{OAC})_{2}$ were purchased from Sigma-Aldrich, $10 \% \mathrm{Ni} / \mathrm{\gamma}-\mathrm{Al}_{2} \mathrm{O}_{3}$ was purchased from Riogen, USA.

\section{Methods}

Synthesis of Cu-PMO catalyst was prepared according to our previously reported procedure. ${ }^{[1]}$ In a typical procedure, a solution containing $\mathrm{AlCl}_{3} \cdot 6 \mathrm{H}_{2} \mathrm{O}(12.07 \mathrm{~g}, 0.05 \mathrm{~mol}), \mathrm{Cu}\left(\mathrm{NO}_{3}\right)_{2} \cdot 2.5 \mathrm{H}_{2} \mathrm{O}(6.98 \mathrm{~g}, 0.03 \mathrm{~mol})$ and $\mathrm{MgCl}_{2} \cdot 6 \mathrm{H}_{2} \mathrm{O}(24.4 \mathrm{~g}, 0.12 \mathrm{~mol})$ in deionized water $(200 \mathrm{~mL})$ was dropwise added to a solution containing $\mathrm{Na}_{2} \mathrm{CO}_{3}$ $(5.30 \mathrm{~g}, 0.05 \mathrm{~mol})$ in water $(300 \mathrm{~mL})$ at $60^{\circ} \mathrm{C}$ under vigorous stirring. The $\mathrm{pH}$ value was always kept between 9 and 10 by addition of small portions of a $1 \mathrm{M}$ solution of $\mathrm{NaOH}$. The mixture was vigorously stirred at $60^{\circ} \mathrm{C}$ for 72 h. After cooling to RT, the light blue solid was filtered and resuspended in a $2 \mathrm{M}$ solution of $\mathrm{Na}_{2} \mathrm{CO}_{3}(300 \mathrm{~mL})$ and stirred overnight at $40^{\circ} \mathrm{C}$. The catalyst precursor was filtered and washed with deionized water until chloride free. After drying the solid for $6 \mathrm{~h}$ at $100{ }^{\circ} \mathrm{C}$ followed by the calcination at $460{ }^{\circ} \mathrm{C}$ for $24 \mathrm{~h}$ in air, $9.5 \mathrm{~g}$ of $\mathrm{Cu}_{20}-\mathrm{PMO}$ was obtained.

Reductive catalytic fractionation of lignocellulosic biomass was carried out in a high-pressure Parr autoclave equipped with an overhead stirrer. Typically, the autoclave was charged with $0.4 \mathrm{~g}$ of $\mathrm{Cu}_{20}$-PMO catalyst, $2 \mathrm{~g}$ of lignocellulose (beech, pine or poplar) and methanol $(20 \mathrm{~mL})$ as a solvent. The reactor was sealed and pressurized with $\mathrm{H}_{2}$ (40 bar) at RT. The reactor was heated to $180^{\circ} \mathrm{C}$ and stirred at $400 \mathrm{rpm}$ for $18 \mathrm{~h}$. After completion of the reaction, the reactor was cooled to RT. Then $0.1 \mathrm{~mL}$ solution was collected through a syringe and injected to GCMS or GC-FID after filtration through a PTFE filter $(0.45 \mu \mathrm{m})$. The solid was separated from the solution by centrifugation and subsequent decantation and additionally washed with methanol $(3 \times 20 \mathrm{~mL})$. The methanol 
extracts were combined in a round bottom flask and the solvent was removed in vacuo. The crude product was dried in a desiccator in vacuo for overnight and was further used as specified below. Fractionation of the crude mixture: To the obtained crude mixture EtOAc $(20 \mathrm{~mL})$ was added and it was stirred for overnight at RT, which resulted in precipitation of brownish colored solid. The suspension was then transferred into a $20 \mathrm{~mL}$ centrifuge tube. The solid was separated by centrifugation and decantation and additionally washed with EtOAc $(2 \times 20 \mathrm{~mL})$. The EtOAc soluble fractions were combined in a round bottom flask and the solvent was removed in vacuo. The soluble and insoluble fractions were additionally dried in vacuo under constant weight. The soluble fraction was washed with small amount of saturated $\mathrm{NaHCO}_{3}(2 \times 10 \mathrm{~mL})$ and brine $(2 \times 10 \mathrm{~mL})$ and dried over anhydrous $\mathrm{MgSO}_{4}$ and further used as specified below.

Demethoxylation/hydrogenation of model compound $1 \mathrm{G}$ to PC was carried out in $100 \mathrm{~mL}$ high-pressure Parr autoclave equipped with an overhead stirrer. Typically, the autoclave was charged with $1 \mathrm{~g}$ Raney Nickel catalyst, $0.2 \mathrm{~g}$ (1.1 mmol) 1G, $15 \mathrm{~mL}$ isopropanol, $20 \mathrm{mg}$ dodecane as internal standard. The reactor was sealed and pressurized with $\mathrm{H}_{2}(10 \mathrm{bar})$ at RT. The reactor was heated to $120^{\circ} \mathrm{C}$ and stirred at $400 \mathrm{rpm}$ for $2 \mathrm{~h}$. After completion of the reaction, the reactor was cooled to RT. Then $0.1 \mathrm{~mL}$ solution was collected through a syringe and injected to GC-MS or GC-FID after filtration through a PTFE filter $(0.45 \mu \mathrm{m})$. The Raney nickel was separated from the solution by centrifugation and subsequent decantation and additionally washed with isopropanol $(3 \times 20$ $\mathrm{mL}$ ). Then the isopropanol soluble fractions were combined in a round bottom flask and the solvent was removed in vacuo. The crude product was dried in a desiccator in vacuo for overnight and was further used as specified below.

Copolymerization of model compound PC with DMFD and DMTA was performed using equal molar ratio of PC and DMTA or DMFD over $\mathrm{Zn}(\mathrm{OAC})_{2}$ or Titanium (IV) butoxide (TBT) catalyst. For example, a $100 \mathrm{~mL}$ three-neck flask equipped with a magnetic stirrer and reflux condenser was charged with $0.53 \mathrm{~g}(3.35 \mathrm{mmol})$ of PC diol, 0.66 $\mathrm{g}(3.35 \mathrm{mmol})$ of DMTA and $1 \mathrm{~mol} \%(0.0057 \mathrm{~g}) \mathrm{Zn}(\mathrm{OAc})_{2}$ catalyst. The esterification reaction was performed at $190{ }^{\circ} \mathrm{C}$ for $1 \mathrm{~h}$ under nitrogen flow. Then, the reaction temperature was increased to $230{ }^{\circ} \mathrm{C}$, the pressure was reduced to $1 \mathrm{mPa}$ using an oil pulp for $1 \mathrm{~h}$ and $3 \mathrm{~h}$, respectively. After that, the reaction mixture was cooled down to $\mathrm{RT}$ and the pressure was returned to atmospheric pressure by introducing nitrogen. The obtained solid was characterized by NMR, DSC, TGA, FTIR and GPC (See Section 3).

Chemical recycling of the synthesized poly (PC, TPA) was carried out in a $100 \mathrm{~mL}$ high pressure Parr autoclave equipped with an overhead stirrer. Typically, the autoclave was charged with poly (PC, TPA) (0.2 g), dodecane (20 $\mathrm{mg}$ ) and methanol $(30 \mathrm{~mL})$. The reactor was sealed and flushed with $\mathrm{N}_{2}$ three times. The reactor was heated to $190{ }^{\circ} \mathrm{C}$ and stirred at $400 \mathrm{rpm}$ for $4 \mathrm{~h}$. After completion of the reaction, the reactor was cooled to RT. The PC-rich mixture was then isolated and purified by column chromatography using EtOAc/n-hexane (1:2 to 1:1 to 2:1).

\section{Characterizations}

NMR spectroscopy: At the University of Groningen, ${ }^{1} \mathrm{H},{ }^{13} \mathrm{C}$ NMR and 2D NMR spectra were recorded on a Varian Mercury Plus 400, Agilent MR 400 (400 and 101 MHz, respectively) and a Bruker Avance NEO 600 (600 and 151 $\mathrm{MHz}$, respectively); At the University of Graz: ${ }^{1} \mathrm{H}$, and ${ }^{13} \mathrm{C}$ NMR spectra were recorded on a Bruker Avance III $300 \mathrm{MHz}$ (300 and $75 \mathrm{MHz}$, respectively) and 2D NMR spectra were recorded on a Bruker Avance III $700 \mathrm{MHz}$ with Cryoplatform and a $5 \mathrm{~mm}$ Triple-Resonance cryoprobe (700 and $175 \mathrm{MHz}$, respectively); Gel Permeation Chromatography (GPC) was performed at the University of Graz on a SHIMADZU NEXERA equipped 2×SDV analytical Linear M $(8 \times 300 \mathrm{~mm}, 5 \mu \mathrm{m})$ plus 1xprecolumn SVD $(8 \times 50 \mathrm{~mm}, 5 \mu \mathrm{m})$. The columns were operated at $40{ }^{\circ} \mathrm{C}$ with a flow-rate of $1 \mathrm{~mL} \cdot \mathrm{min}^{-1}$ of THF. Detection was accomplished at $40{ }^{\circ} \mathrm{C}$ u using an SPD-M40 photoarray detector in series. The molecular weight estimations were performed using polystyrene standards of known molecular weight distribution. Thermogravimetric analysis (TGA) was performed on a Netzsch Jupiter STA 449C thermogravimetric analyzer. Typically, the sample $(1-3 \mathrm{mg})$ was weighed into a platinum pan. The sample was heated from 20 to $550^{\circ} \mathrm{C}$ with a heating rate of $10^{\circ} \mathrm{C} \cdot \mathrm{min}^{-1}$ under $\mathrm{N}_{2}$ flow with a flow rate of $20 \mathrm{~mL} \cdot \mathrm{min}^{-1}$. The 
temperatures were recorded when $5 \%$ weight loss $\left(T_{5 \%}\right)$ and $90 \%$ weight loss rate $\left(T_{90}\right)$ occurred. Differential Scaning Calorimetry (DSC) was conducted on a Perkin Elmer DSC 8500. In a typical procedure, the sample (5-10 $\mathrm{mg}$ ) was weighed into a DSC pan and then capped with a lid. The sample was sealed and heated from 25 to $250{ }^{\circ} \mathrm{C}$ with a heating rate of $10^{\circ} \mathrm{C} \cdot \mathrm{min}^{-1}$. Then, it was cooled to $25^{\circ} \mathrm{C}$ with a heating rate of $10{ }^{\circ} \mathrm{C} \cdot \mathrm{min}^{-1}$. Subsequently, a second heating scan to $250^{\circ} \mathrm{C}$ with the same heating rate was performed. All of experiments were performed under $\mathrm{N}_{2}$ flow with a flow rate of $20 \mathrm{~mL} \cdot \mathrm{min}^{-1}$.

\section{Conflicts of interest}

There are no conflicts to declare.

\section{Acknowledgements}

K. B. is grateful for financial support from the European Research Council, ERC Starting Grant 2015 (CatASus) 638076 and ERC Proof of Concept Grant 2019 (PURE) 875649. This work is part of the research programme Talent Scheme (Vidi) with project number 723.015.005, which is partly financed by The Netherlands Organization for Scientific Research (NWO). X. W. is grateful for financial support from the China Scholarship Council (grant number 201808330391).

\section{Contributions}

X. Y. W. designed and performed all related experiments. X. Y. W. also contributed to data collection, data analysis, structural analysis of polymer and manuscript preparation. Z. H. S. conceived the idea of targeting PC by funneling for polymer purposes and co-supervised the work; Z.H.S and M.V.G performed exploratory catalytic experiments towards funneling. M. V. G. performed reaction kinetics analysis, structural analysis of polymer and manuscript revision. K. B. contributed to data interpretation, experimental design and design of figures, supervised the research and wrote the manuscript. All authors commented on and approved the final manuscript.

The authors thank Dr. Markus Hochegger for the help with the fractional distillation. X.Y.W also thanks Dr Anastasiia Afanasenko for the useful discussions.

\section{Reference}

1. PP-Admin, PET - A review of material developments, https://www.hbmedia.info/petplanet/2019/09/04/peta-review-of-material-developments/, (accessed July 20, 2020)

2. Geyer, R., Jambeck, J. R. \& Law, K. L. Production, use, and fate of all plastics ever made. Sci. Adv.3, e1700782 (2017).

3. White paper US EPA:

https://www.epa.gov/sites/production/files/2017-02/documents/tfw-trash free waters plastics-aquaticlife-report-2016-12.pdf.

4. Jambeck, J. R., Jambeck, J. R., Geyer, R., Wilcox, C., Siegler, T. R., Perryman, M., Andrady, A., Narayan, R. \& Law, K. L. Plastic waste inputs from land into the ocean. Science 347, 768-771 (2015).

5. https://dokumen.tips/documents/pet-production-technical-reportpdf.

6. Tang, X. Y. \& Chen, E. Y. X. Toward Infinitely Recyclable Plastics Derived from Renewable Cyclic Esters. Chem 5, 284-312 (2019).

7. Hatti-Kaul, R., Nilsson, L. J., Zhang, B. Z., Rehnberg, N. \& Lundmark, S. Designing Biobased Recyclable Polymers for Plastics. Trends Biotechnol. 38, 50-67 (2020).

8. Rorrer, N. A., Nicholson, S., Carpenter, A., Biddy, M. J., Grundl, N. J. \& Beckham, G. T. Combining Reclaimed PET with Bio-based Monomers Enables Plastics Upcycling. Joule 3, 1006-1027 (2019). 
9. Nguyen, H. T. H., Qi, P. X., Rostagno, M., Feteha, A. \& Miller, S. A. The quest for high glass transition temperature bioplastics. J. Mater. Chem. A 6, 9298-9331 (2018).

10. Nakajima, H., Dijkstra, P. \& Loos, K. The Recent Developments in Biobased Polymers toward General and Engineering Applications: Polymers that Are Upgraded from Biodegradable Polymers, Analogous to Petroleum-Derived Polymers, and Newly Developed. Polymers 9, 523 (2017).

11. Li, H., Riisager, A., Saravanamurugan, S., Pandey, A., Sangwan, R. S., Yang, S. \& Luque, R. Carbon-increasing catalytic strategies for upgrading biomass into energy-intensive fuels and chemicals. ACS Catal. 8, 148-187 (2018).

12. Stahel, W. R. Nature, 531, 435 (2016).

13. Circular economy to have considerable benefits, but challenges remain - European Environment Agency, https://www.eea.europa.eu/highlights/circular-economy-to-have-considerable

14. EU white paper

https://www.efpia.eu/media/25818/efpia-white-paper-on-circular-economy-oct-2016 final.pdf

15. DOE report

https://www.energy.gov/sites/default/files/2020/08/f77/beto-amo-mars-plastics-wksp-rpt-final.pdf

16. Stadler, B. M., Wulf, C., Werner, T., Tin, S. \& de Vries, J. G. Catalytic approaches to monomers for polymers based on renewables. ACS Catal. 9, 8012-8067 (2019).

17. De Clercq, R., Dusselier, M. \& Sels, B. Heterogeneous catalysis for bio-based polyester monomers from cellulosic biomass: advances, challenges and prospects. Green Chem. 19, 5012-5040 (2017).

18. Jing, Y. X., Wang, Y. Q., Furukawa, S. Y., Xia, J., Sun, C. Y., Hulsey, M. J., Wang, H. F., Guo, Y., Liu, X. H. \& Yan, N. Towards the Circular Economy: Converting Aromatic Plastic Waste Back to Arenes over a $\mathrm{Ru} / \mathrm{Nb}_{2} \mathrm{O}_{5}$ Catalyst. Angew. Chem. Int. Ed. 133, 5587-5595 (2021).

19. Guo, Z., Yan, N. \& Lapkin, A. A. Towards circular economy: integration of bio-waste into chemical supply chain. Curr. Opin. Chem. Eng. 26, 148-156 (2019).

20. https://www.avantium.com/wp-content/uploads/2019/11/Article-PEF-Planet-Insider-issue-09-2019-page40.pdf

21. Motagamwala, A. H., Won, W. Y., Sener, C., Alonso, D. M., Maravelias, C. T. \& Dumesic, J. A. Toward biomassderived renewable plastics: Production of 2, 5-furandicarboxylic acid from fructose. Sci. adv. 4, eaap9722 (2018).

22. Ji, N., Zhang, T., Zheng, M. Y., Wang, A. Q., Wang, H., Wang, X. D., Chen, J. G. G. Direct catalytic conversion of cellulose into ethylene glycol using nickel-promoted tungsten carbide catalysts. Angew. Chem. Int. Ed. 120, 8638-8641 (2008).

23. Wang, A. \& Zhang, T. One-pot conversion of cellulose to ethylene glycol with multifunctional tungsten-based catalysts. Acc. Chem. Res. 46, 1377-1386 (2013).

24. Song, S., Zhang, J., Gözaydın, G. \& Yan, N. Production of terephthalic acid from corn stover lignin. Angew. Chem. Int. Ed. 58, 4934-4937 (2019).

25. Pang, J., Zheng, M., Sun, R., Wang, A., Wang, X. \& Zhang, T. Synthesis of ethylene glycol and terephthalic acid from biomass for producing PET. Green Chem. 18, 342-359 (2016).

26. Patet, R. E., Nikbin, N., Williams, C. L., Green, S. K., Chang, C.-C., Fan, W., Caratzoulas, S., Dauenhauer, P. J. \& Vlachos, D. G. Kinetic regime change in the tandem dehydrative aromatization of furan Diels-Alder products. ACS Catal. 5, 2367-2375 (2015).

27. Pacheco, J. J. \& Davis, M. E. Synthesis of terephthalic acid via Diels-Alder reactions with ethylene and oxidized variants of 5-hydroxymethylfurfural. PNAS 111, 8363-8367 (2014).

28. Nguyen, H. T. H., Short, G. N., Qi, P. \& Miller, S. A. Copolymerization of lactones and bioaromatics via concurrent ring-opening polymerization/polycondensation. Green Chem. 19, 1877-1888 (2017). 
29. Nguyen, H. T. H., Reis, M. H., Qi, P. \& Miller, S. A. Polyethylene ferulate (PEF) and congeners: polystyrene mimics derived from biorenewable aromatics. Green Chem. 17, 4512-4517 (2015).

30. Abu-Omar, M. M., Barta, K., Beckham, G. T., Luterbacher, J. S., Ralph, J., Rinaldi, R., Roman-Leshkov, Y., Samec, J. S. M., Sels, B. F. \& Wang, F. Guidelines for performing lignin-first biorefining. Energy Environ. Sci. 14, 262292 (2021).

31. Questell-Santiago, Y. M., Galkin, M. V., Barta, K. \& Luterbacher, J. S. Stabilization strategies in biomass depolymerization using chemical functionalization. Nat. Rev. Chem. 4, 311-330 (2020).

32. Renders, T., Van den Bossche, G., Vangeel, T., Van Aelst, K. \& Sels, B. F. Reductive catalytic fractionation: state of the art of the lignin-first biorefinery. Curr. Opin. Biotechnol. 56, 193-201 (2019).

33. Galkin, M. V. \& Samec, J. S. Lignin valorization through catalytic lignocellulose fractionation: a fundamental platform for the future biorefinery. ChemSusChem 9, 1544-1558 (2016).

34. Schutyser, W., Van den Bosch, S., Dijkmans, J., Turner, S., Meledina, M., Van Tendeloo, G., Debecker, D. P. \& Sels, B. F. Selective nickel-catalyzed conversion of model and lignin-derived phenolic compounds to cyclohexanone-based polymer building blocks. ChemSusChem 8, 1805-1818 (2015).

35. Schutyser, W., Van den Bossche, G., Raaffels, A., Van den Bosch, S., Koelewijn, S. F., Renders, T. \& Sels, B. F. Selective conversion of lignin-derivable 4-alkylguaiacols to 4-alkylcyclohexanols over noble and non-noblemetal catalysts. ACS Sustain. Chem. Eng. 4, 5336-5346 (2016).

36. Koelewijn, S. F., Van den Bosch, S., Renders, T., Schutyser, W., Lagrain, B., Smet, M., Thomas, J., Dehaen, W., Van Puyvelde, P., Witters, H. \& Sels, B. F. Sustainable bisphenols from renewable softwood lignin feedstock for polycarbonates and cyanate ester resins. Green Chem. 19, 2561-2570 (2017).

37. Koelewijn, S. F., Cooreman, C., Renders, T., Saiz, C. A., Van den Bosch, S., Schutyser, W., De Leger, W., Smet, M., Van Puyvelde, P., Witters, H., Van der Bruggen, B. \& Sels, B. F. Promising bulk production of a potentially benign bisphenol A replacement from a hardwood lignin platform. Green Chem. 20, 1050-1058 (2018).

38. Wang, S., Shuai, L., Saha, B., Vlachos, D. G. \& Epps III, T. H. From tree to tape: direct synthesis of pressure sensitive adhesives from depolymerized raw lignocellulosic biomass. ACS Central Sci. 4, 701-708 (2018).

39. Liao, Y. H., Koelewijn, S. F., Van den Bossche, G., Van Aelst, J., Van den Bosch, S., Renders, T., Navare, K., Nicolai, T., Van Aelst, K., Maesen, M., Matsushima, H., Thevelein, J. M., Van Acker, K., Lagrain, B., Verboekend, D. \& Sels, B. F. A sustainable wood biorefinery for low-carbon footprint chemicals production. Science 367, 1385-1390 (2020).

40. Linger, J. G., Vardon, D. R., Guarnieri, M. T., Karp, E. M., Hunsinger, G. B., Franden, M. A., Johnson, C. W., Chupka, G., Strathmann, T. J., Pienkos, P. T. \& Beckham, G. T. Lignin valorization through integrated biological funneling and chemical catalysis. PNAS 111, 12013-12018 (2014).

41. Schutyser, W., Renders, T., Van den Bosch, S., Koelewijn, S. F., Beckham, G. T. \& Sels, B. F. Chemicals from lignin: an interplay of lignocellulose fractionation, depolymerisation, and upgrading. Chem. Soc. Rev. 47, 852908 (2018).

42. Perez, J. M., Kontur, W. S., Alherech, M., Coplien, J., Karlen, S. D., Stahl, S. S., Donohue, T. J. \& Noguera, D. R. Funneling aromatic products of chemically depolymerized lignin into 2-pyrone-4-6-dicarboxylic acid with Novosphingobium aromaticivorans. Green Chem. 21, 1340-1350 (2019).

43. Sun, Z., Bottari, G., Afanasenko, A., Stuart, M. C., Deuss, P. J., Fridrich, B. \& Barta, K. Complete lignocellulose conversion with integrated catalyst recycling yielding valuable aromatics and fuels. Nat. Catal. 1, 82-92 (2018).

44. Wang, X., Rinaldi, R. \& Exploiting, H. transfer reactions with Raney Ni for upgrade of phenolic and aromatic biorefinery feeds under unusual, low-severity conditions. Energy Environ. Sci. 5, 8244-8260 (2012).

45. Elangovan, S., Afanasenko, A., Haupenthal, J. r., Sun, Z., Liu, Y., Hirsch, A. K. \& Barta, K. From wood to tetrahydro-2-benzazepines in three waste-free steps: modular synthesis of biologically active lignin-derived scaffolds. ACS Central Sci. 5, 1707-1716 (2019). 
46. Mialon, L., Pemba, A. G. \& Miller, S. A. Biorenewable polyethylene terephthalate mimics derived from lignin and acetic acid. Green Chem. 12, 1704-1706 (2010).

47. https://scifinder.cas.org/scifinder/view/scifinder/scifinderExplore.jsf $\quad$ Search C-NMR for 1,4Benzenedicarboxylic acid, 1,4-dicyclohexyl ester (CAS Registry Number 18699-51-9)

48. Nishii, Y., Hirai, T., Fernandez, S., Knochel, P. \& Mashima, K. Zinc-Catalyzed Esterification of N- $\beta$ Hydroxyethylamides: Removal of Directing Groups under Mild Conditions. Eur. J. Org. Chem. 2017, 5010-5014 (2017).

49. https://en.wikipedia.org/wiki/Polyethylene terephthalate

50. Yue, F., Lu, F., Regner, M., Sun, R. \& Ralph, J. Lignin-derived thioacidolysis dimers: reevaluation, new products, authentication, and quantification. ChemSusChem 10, 830-835 (2017).

51. Van den Bosch, S. et al. Reductive lignocellulose fractionation into soluble lignin-derived phenolic monomers and dimers and processable carbohydrate pulps. Energy Environ. Sci. 8, 1748-1763 (2015).

52. Van den Bosch, S. et al. Integrating lignin valorization and bio-ethanol production: on the role of $\mathrm{Ni}^{-\mathrm{Al}_{2} \mathrm{O}_{3}}$ catalyst pellets during lignin-first fractionation. Green Chem. 19, 3313-3326 (2017). 